\title{
An investigation on the cutting force of milling Inconel 718
}

\author{
Jhy-Cherng Tsai ${ }^{1}$,, Chung-Yu Kuo ${ }^{1}$, Zing-Ping Liu ${ }^{1}$ and Kelvin Hsi-Hung Hsiao ${ }^{2}$ \\ ${ }^{1}$ Department of Mechanical Engineering, National Chung-Hsing University, Taiwan \\ ${ }^{2}$ Intelligent Machinery Center, Industrial Technology Research Institute, Taiwan
}

\begin{abstract}
Inconel alloy has been widely used in industry but is difficult to machine due to its rapid change in cutting force during machining. This paper investigated the cutting force for milling Inconel 718 as conventional force model is unable to handle the above situation. Theorectical force model is first reviewed and two-phase experiments of slot milling based on dry cutting are designed to measure the cutting force and the specific cutting force. Experiments in phase I are designed based on Taguchi method with spindle speed, feedrate per cutting edge and depth of cut as experimental parameters. The results showed that the first two parameters play more important roles in the cutting force. A phase II exhaust experiments is designed with spindle speed set from 400 to $800 \mathrm{rpm}$ while the feedrate per cutting edge is set from 0.04 to $0.08 \mathrm{~mm} /$ tooth. The results are concluded as the following. (i) There exists a strong size effect in milling Inconel 718 as the cutting force changed with the chip thickness. Specific cutting force is larger at small thickness of cut and become smaller when the thickness increases. (ii) $\mathrm{A} 2^{\text {nd }}$ order non-linear cutting force model, which takes spindle speed $N$ and feedrate $f_{z}$ into account, for milling Inconel 718 is derived from the measured data and represented as $F_{t}\left(N, f_{z}\right)=\left(13910-3.1 N-109900 f_{z}-0.0028 N^{2}+23.9 N f_{z}+434500 f_{z}^{2}\right) \times a_{p} \times h$. The derived force model compensates the inaccuracy of conventional force model.
\end{abstract}

\section{Introduction}

Nicle-based alloy has been widely emplyed in the aerospace and marine industries because of its good physical and chemical properties, including high-temperature strength, thermal stability, corrotion resistance and high endurance strengthy. It is commonly used in jet engine and rotor due to these excellent properties. Such Nicle-based alloys are thus called as super alloys and Inconel is the commonly used one among these alloys. Inconel is a typical anti-correotion material and contains $50 \%$ to $55 \%$ Nickle(Ni) with $17 \%$ to $21 \%$ Chromium(Cr) and a few other elements such as Cobalt(Co) and Molybdenum(Mo) for different applications. It maintains high strength at high temperature with good anti-creep and endurance properties. It is therefore difficult to machine due to these properties.

While aerospace components require good precision, machining is the most commonly and widely employed process in fabricating these components. The machinability of Inconel, on the other hand, is poor due to these good performance[1,2]. Such difficult-to-machine material is hard to machine due to strain hardening and often results in high tool wear rate and built-up-edge thus downgrades surface quality. It is an crucial issue how to solve these problems for aerospace and machining industries. This paper is aimmed to investigate the cutting force of machining Inconel super alloy as cutting force

${ }^{\text {a }}$ Corresponding author : jctsai@mail.nchu.edu.tw

(C) The Authors, published by EDP Sciences. This is an open access article distributed under the terms of the Creative Commons Attribution License 4.0 (http://creativecommons.org/licenses/by/4.0/). 
reflects the material properties as well as cutting conditions that are highly related to product quality and tool management. As machining of Inconel is often a know-how of a company, very few literatures investigated the detail of cutting force. We start with analysis of cutting force of a milling proccess and machining parameters that plays important role in straining hardening effect. Experiments are then designed, based on the Taguchi method, and conducted to collect cutting forces. A model of the cutting force, as a function of machining parameters, is then derived.

\section{Analysis of milling force}

Milling process is a conventional material removal process. Figure 1(a) shows the milling process that the workpiece moves across the rotating spindle and material is removed by the cutter attached to the spindle. The tangetail cutting forces $\mathbf{F}_{\mathbf{t}}$, or the effective cutting force in material removal as illustrated in Figure 1(b), of a cutting edge in the process is the specific cutting force, $k_{s}$, multiplied by the material removal. The material removed is the depth of cut $a_{p}$ (in axial dirction) multiplies the instant thickness of cut $h$ (in radial direction). As a result, $\mathbf{F}_{\mathbf{t}}$ can be derived as shown in eqution 1 where $\mathbf{n}_{\mathbf{t}}$ represents the unit vector in tangentail direction. The instant thickness of cut $h$ can be further represented as a function of the roating displacement $\varphi$ and the feed per cutting edge $f_{z}$ as shown in equation $2[3,4]$.

$$
\begin{gathered}
\mathbf{F}_{\mathbf{t}}=k_{s} \times a_{p} \times h \mathbf{n}_{\mathbf{t}} \\
h=f_{z} \times \sin \varphi
\end{gathered}
$$

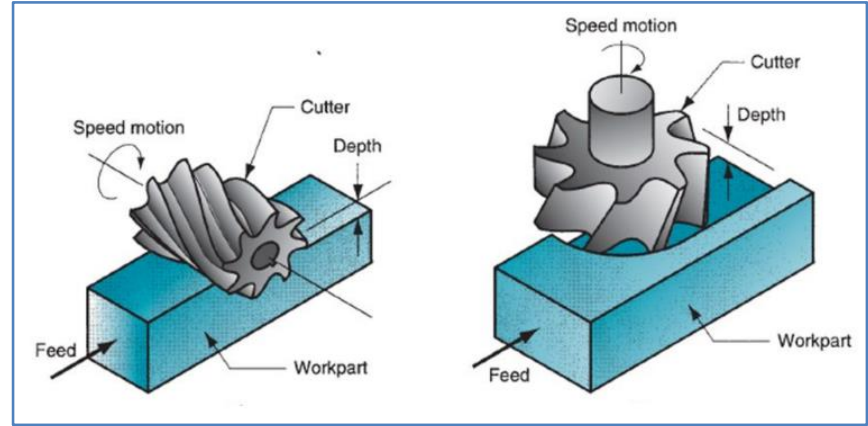

(a)

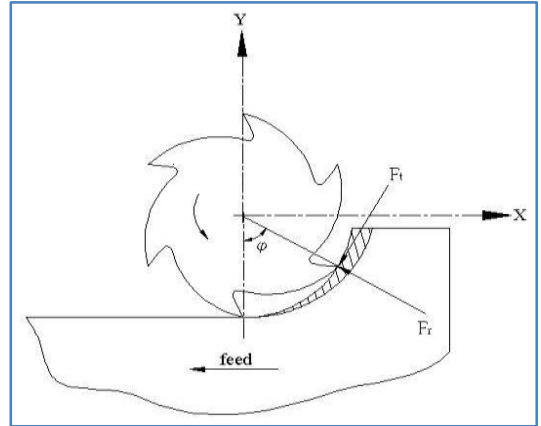

(b)

Figure 1. Illustration of (a) milling process and (b) tangential cutting forces in an up milling process [3, 4].

The radial cutting force $\mathrm{F}_{\mathrm{r}}$ is usually presented as a ratio $k_{r}$ to the tangentail cutting force $\mathrm{F}_{\mathrm{t}}$. Tlusty $\&$ MacNeil [5] showed that, based on their experimental data, $k_{r}$ is around 0.3 for most metals. For a milling process with multiple cutting edges engaged, the tangetial and radial cutting forces are the vector sum of tangetial and radial cutting forces of each individual cutting edge. However, Inconel alloy is difficult to maching mainly because of its high strain hardening and high strength at high temperature [6]. The above two equations do not well match experimental data thus a modified model is required.

Rahman et al[1] noticed that tool life decreases when the cutting speed increases in his turning Inconel 718 experiment. He proposed this is caused by the friction heat between the chip and the tool as heat geneartion increases as cutting speed increases. Li[7], in milling Inconel 718, also noticed that flank wear is the major factor reducing tool life and tool wears faster in up-milling. Nalbant et al[8], when turning Inconel 718, found that cutting force increases as cutting speed increases though speed is not an explicit factor affecting cutting force in the theorectical model shown in equation 1 . Liao et al[9], in their investigation on the slot milling and side milling, found that high cutting temperature and difficulty in chip disposal are two main problems encountered in high-speed end milling of Inconel 718. Thakur et al [10] found that tool life, in turning Inconel 718, was affected by the cutting 
speed, feed rate and tool type while depth of cut, in addition to the first two factors, also affects material hardening. A similar result is also reported in D'Addona et al [11] that tool wear increased rapidly at high cutting speed was observed though surface finish does not change much.

Some other researchers, such as Choudhury \& El-Baradie [2], Sharman et al [12] and Devillez et al [13] noticed that tool life is highly reduced in machining Inconel alloy if the cutting parameters are not well selected. They used cutting tools with various coating films in machining Inconel tests and found that tools with coating films perfomes better then regular tools when the depth of cut is higher then $1.0 \mathrm{~mm}$. Among many cutting parameters, depth of cut and feed rate, rather than cutting speed, are two major factors affecting tool wear. Furthermore, tools coated with TiAlN performs the best among many other coating films [12].

As most literatures emphasized investigating tool wear and tool life, cutting force is the more fundamental index needed to be investigated as it reflects not only tool wear but also machining and material conditions. In particular, a suitable cutting force model based on equations 1 and 2 is required to serve this purpose.

\section{Phase I experimental design and results}

As the purpose is to find a modified cutting force model considering different cutting parameters, we started with the root cause analysis of cutting force for Inconel 718. In this investigation, we conducted two phases of experiments. In the first phase, we wanted to find important parameters that affecting cutting force as well as their ranges. A list of experiments are then designed to further investigate the effect of major parameters.

In the first phase, we began with slot cutting experimental design by Taiguchi method [14] in order to reduce the number of experiments. While cutting force is strongly related to the material removal rate, the depth of cut $a_{p}$, feed rate per cutting edge $f_{z}$ and spindle speed $N$ are three factors used in designing the experiments. Three levels of each parameter are designed based on machining parameters provided by the cutting tool maker. A list of experiments are designed using the Taguchi $\mathrm{L}_{9}\left(3^{3}\right)$ orthogonal array as shown in Table 1 where the corresponding feed rate and cutting speed are calculated from the cutting parameters with a $\phi 16 \mathrm{~mm}$ end mill.

Table 1. Experimental design by the Taguchi $\mathrm{L}_{9}\left(3^{3}\right)$ orthogonal array in phase I.

\begin{tabular}{|c|c|c|c|c|}
\hline No. & $\begin{array}{c}\text { spindle speed } \\
N(\mathrm{rpm})\end{array}$ & $\begin{array}{c}\text { feedrate per } \\
\text { cutting edge } f_{z} \\
(\mathrm{~mm} / \text { tooth })\end{array}$ & $\begin{array}{c}\text { depth of cut } a_{p} \\
(\mathrm{~mm})\end{array}$ & $\begin{array}{c}\text { corresponding } \\
\text { feed rate } \\
(\mathrm{mm} / \mathrm{min})\end{array}$ \\
\hline 1 & 400 & 0.02 & 0.1 & 16 \\
\hline 2 & 400 & 0.04 & 0.3 & 32 \\
\hline 3 & 400 & 0.06 & 0.5 & 48 \\
\hline 4 & 500 & 0.04 & 0.1 & 40 \\
\hline 5 & 500 & 0.06 & 0.3 & 60 \\
\hline 6 & 500 & 0.02 & 0.5 & 20 \\
\hline 7 & 600 & 0.06 & 0.1 & 72 \\
\hline 8 & 600 & 0.02 & 0.3 & 24 \\
\hline 9 & 600 & 0.04 & 0.5 & 48 \\
\hline
\end{tabular}

Experiments are conducted in a CNC machining center with rated power $21 \mathrm{KW}$ and maximum spindle speed 14,000rpm. The workpiece material used in the experiment is Inconel 718 and the cutting tool is a $\phi 16 \mathrm{~mm}$ flat end mill with Kennametal Mill4 inserts coated with TiAlN. Cutting force is measured by a Kistler $9124 \mathrm{~B}$ dynamometer with measuring capacities $\pm 20 \mathrm{KN}$ in radial direction 
and $\pm 30 \mathrm{KN}$ in axial direction. The natural frequency of the dynamometer is $1 \mathrm{kHz}$ and the sensitivities are $0.5 \mathrm{mV} / \mathrm{N}$ and $0.33 \mathrm{mV} / \mathrm{N}$ in radial and axial directions. Figure 2 shows the machine tool and the dynamometer used in the experiment. Figure 3 shows experiment setup and detailed dynamometer setup on the spindle.
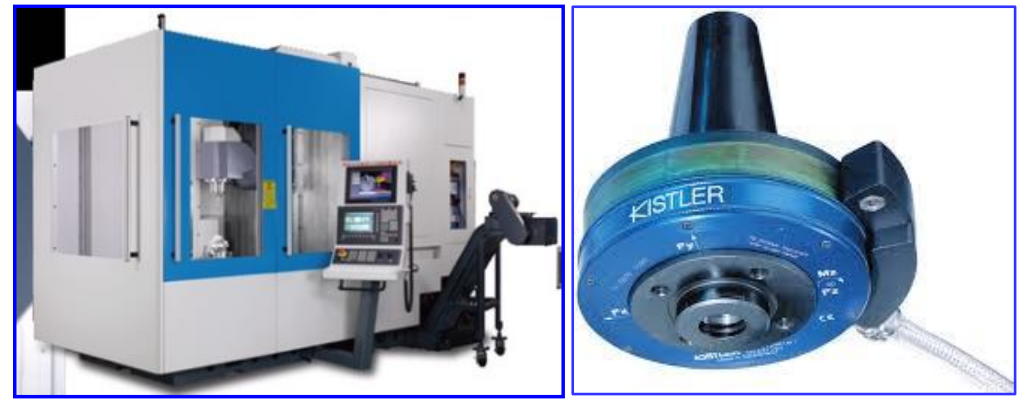

Figure 2. CNC Machining center (left) and dynamometer (right) used in the experiment.
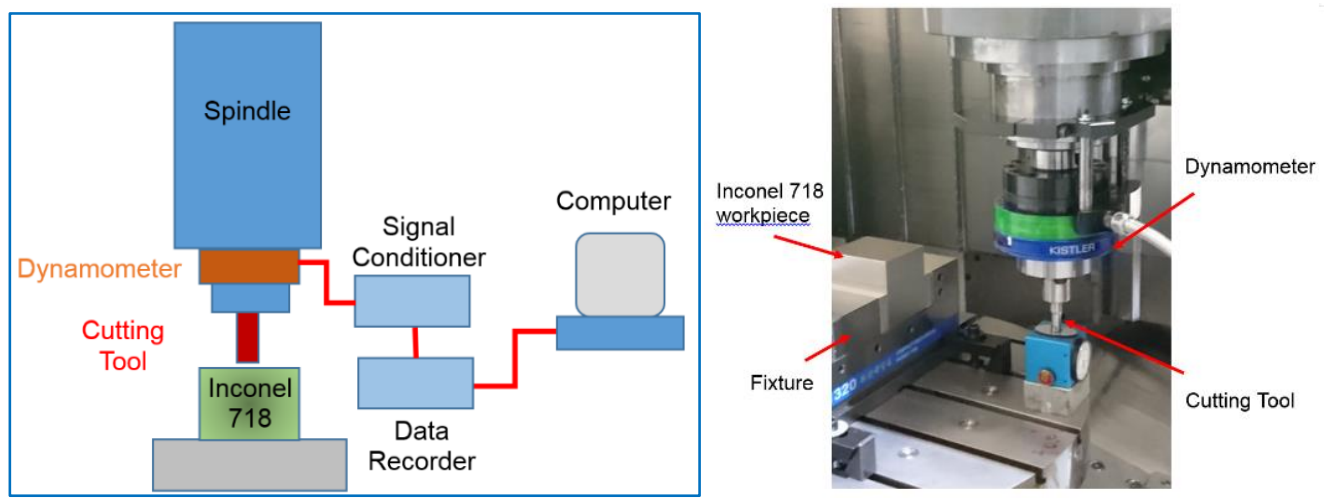

Figure 3. Illustration of experiment setup (left) and setup of dynamometer on the spindle (right).

The measured cutting force signal, as shown in the left in figure 4 , is filtered first. The filtered signal is shown at the right of figure 4 which showed the tangential and radial forces in the milling process. Data from the phase I experiment are collected and calculated by ANOVA (analysis of variance) [14]. Table 2 shows the response of each parameter. The result indicated both spindle speed $N$ and feedrate per cutting edge $f_{z}$ have higher impact on the cutting force. A second phase experiments is then designed in order to investigate the effectiveness of both parameters.

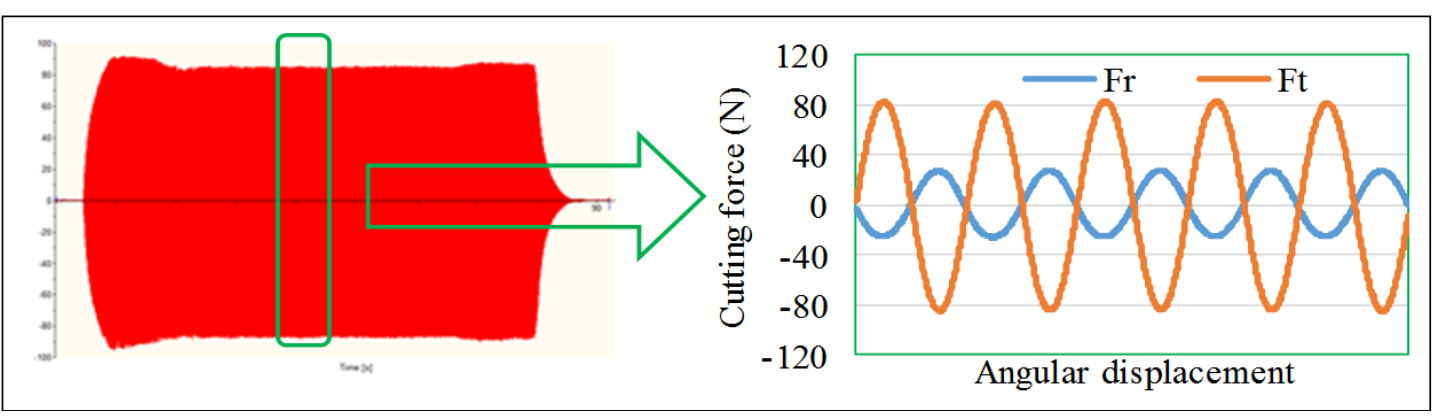

Figure 4. Measured cutting forces (left) and enlarged signal after filtering (right). 
Table 2. Response of parameters in phase I experiment by ANOVA.

\begin{tabular}{|c|c|c|c|}
\hline Level Parameter & $\begin{array}{l}\text { spindle } \\
\text { speed } N\end{array}$ & $\begin{array}{l}\text { feedrate per } \\
\text { cutting edge } f_{z}\end{array}$ & $\begin{array}{c}\text { depth of } \\
\text { cut } a_{p}\end{array}$ \\
\hline 1 & -32.28 & -32.23 & -32.26 \\
\hline 2 & -32.53 & -32.15 & -32.32 \\
\hline 3 & -32.01 & -32.44 & -32.24 \\
\hline Max-Min & 0.52 & 0.29 & 0.08 \\
\hline
\end{tabular}

\section{4 phase II experiment and results}

In phase II experimental design, we emphosized on the detailed data of cutting forces because the instant thickness of feedrate per cutting edge $h$ keeps change in the milling process. As the machining parameters are reduced to two, we expanded the experiment number to do exhaust experiments with spindle speed set to 400 to $800 \mathrm{rpm}$, with interval $100 \mathrm{rpm}$, while the feedrate per cutting edge is set as 0.04 to $0.08 \mathrm{~mm} /$ tooth, with interval $0.01 \mathrm{~mm} /$ tooth. The parameters of the 25 experiments are shown in table 3. Each parameter set is experimented three times to confirm the repeatability. The evaluation index is also changed from cutting forces to the specific cutting force $k_{s}$ in order to nomalizing the effect of parameters. $k_{s}$ is defined in equation 1 can be rewritten to equation 3 .

$$
k_{s}=\mathrm{F}_{\mathrm{t}} /\left(a_{p} \times f_{z} \times \sin \varphi\right)
$$

Table 3. Experimental design at constant $a_{p}$ in phase II.

\begin{tabular}{|c|c|c|c|c|c|}
\hline No. & $\begin{array}{c}\text { spindle speed } \\
N(\mathrm{rpm})\end{array}$ & $\begin{array}{c}\text { feedrate per } \\
\text { cutting edge } f_{z} \\
(\mathrm{~mm} / \text { tooth) }\end{array}$ & No. & $\begin{array}{c}\text { spindle speed } \\
N(\mathrm{rpm})\end{array}$ & $\begin{array}{c}\text { feedrate per } \\
\text { cutting edge } f_{z} \\
(\mathrm{~mm} / \text { tooth) }\end{array}$ \\
\hline 1 & 400 & 0.04 & 14 & 600 & 0.07 \\
\hline 2 & 400 & 0.05 & 15 & 600 & 0.08 \\
\hline 3 & 400 & 0.06 & 16 & 700 & 0.04 \\
\hline 4 & 400 & 0.07 & 17 & 700 & 0.05 \\
\hline 5 & 400 & 0.08 & 18 & 700 & 0.06 \\
\hline 6 & 500 & 0.04 & 19 & 700 & 0.07 \\
\hline 7 & 500 & 0.05 & 20 & 700 & 0.08 \\
\hline 8 & 500 & 0.06 & 21 & 800 & 0.04 \\
\hline 9 & 500 & 0.07 & 22 & 800 & 0.05 \\
\hline 10 & 500 & 0.08 & 23 & 800 & 0.06 \\
\hline 11 & 600 & 0.04 & 24 & 800 & 0.07 \\
\hline 12 & 600 & 0.05 & 25 & 800 & 0.08 \\
\hline 13 & 600 & 0.06 & & & \\
\hline
\end{tabular}

The specific cutting force $k_{s}$ changed with the instant thickness of cut $h$ which is further a function of rotating displacement. As data collected at the beginning ( 0 degree) and the end (180 degree) of the cut are relatively small due to small thickness, signal variations at the two places thus become large and are not suitable to use. We calculated $k_{s}$ starting from 15 degree upto 168 degree. The result of $k_{s}$ with repect to angular displacement $\varphi$ at different feedrate is shown in figure 5. This figure shows that $k_{s}$ is larger at small thickness of cut, the condition near both ends in the curve, and become 
smaller when the thickness of cut increases (at the center of curve). This size effect is critical for machining super alloys similar to Inconel.

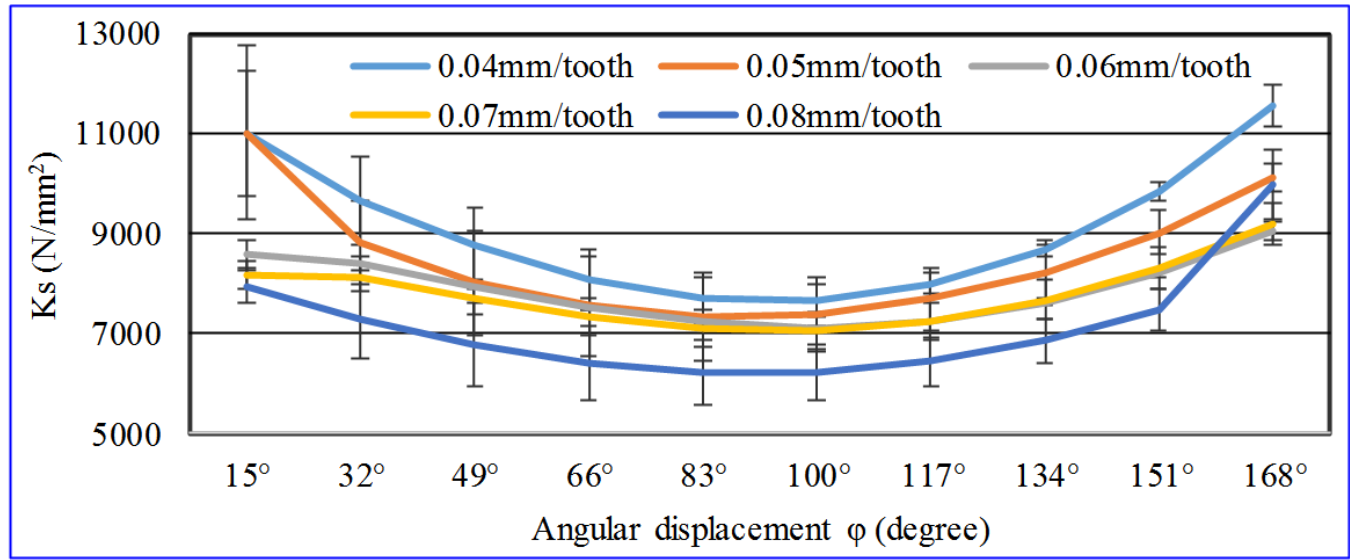

(a)

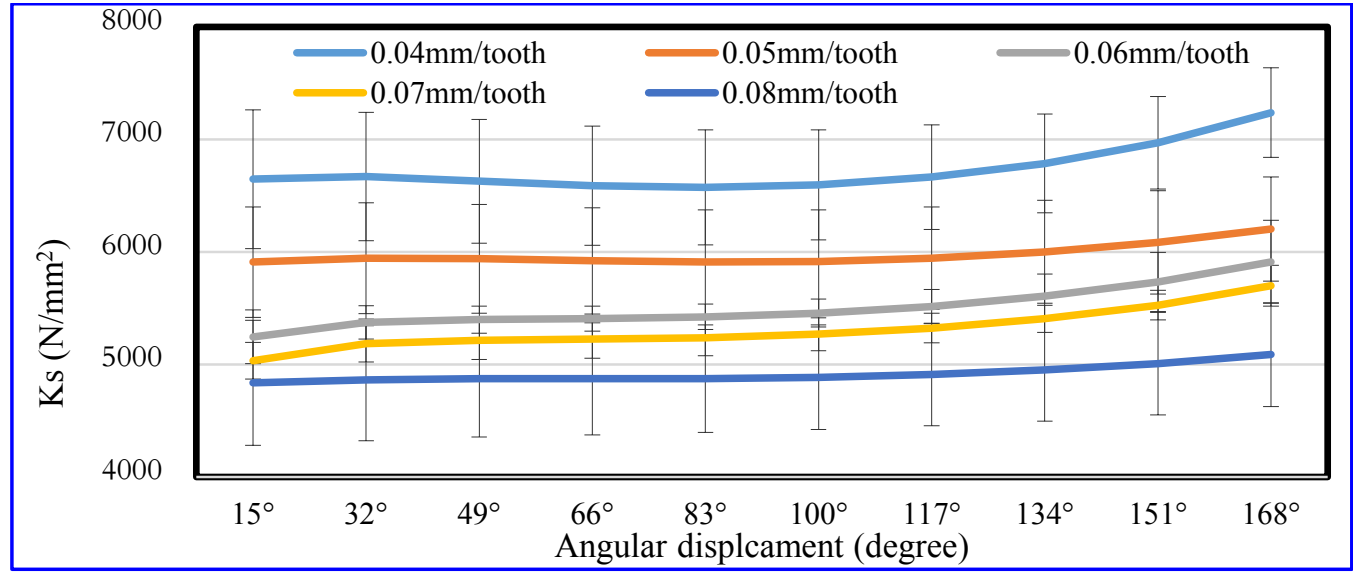

(b)

Figure 5. Specific cutting force $k_{s}$ changed with spindle angular displacement $\varphi$ at different feedrate under (a) $400 \mathrm{rpm}$ and (b) at $800 \mathrm{rpm}$ respectively.

The specific cutting force $k_{s}$ changed not only with the instant thickness of cut but also with the spindle speed $N$ and the feedrate per cutting egde $f_{z}$. Based on the experimental results, $k_{s}$ is represented as a function of $N$ and $f_{z}$, which is plotted in figure 5 where the surface is fitted with measured data shown as blue dots close to the fitted surface. The mean square error (MSE) is 387.9 corresponding to $4.8 \%$ error for specific cutting force at $8000 \mathrm{~N} / \mathrm{mm}^{2}$. The fitted function is represented as in equation 4 that corrects equation 1 and takes cutting speed and feed rate into account. Cutting force $\mathbf{F}_{\mathbf{t}}$, based on equation 1 , is modelled as equation 6 . The equation shows that cutting force is strongly dependant upon machining parameters, in particular the feed per cutting edge $f_{z}$ and the rotating speed $N . f_{z}$ represents the size effect that tells the specific cutting force is enlarged at small feed though the material removal is small.

$$
\begin{gathered}
k_{s}(N, f z)=13910-3.1 N-109900 f_{z}-0.0028 N^{2}+23.9 N f_{z}+434500 f_{z}^{2} \\
\mathbf{F}_{\mathbf{t}}(N, f z)=k_{s}(N, f z) \times a_{p} \times h \mathbf{n}_{\mathbf{t}}
\end{gathered}
$$




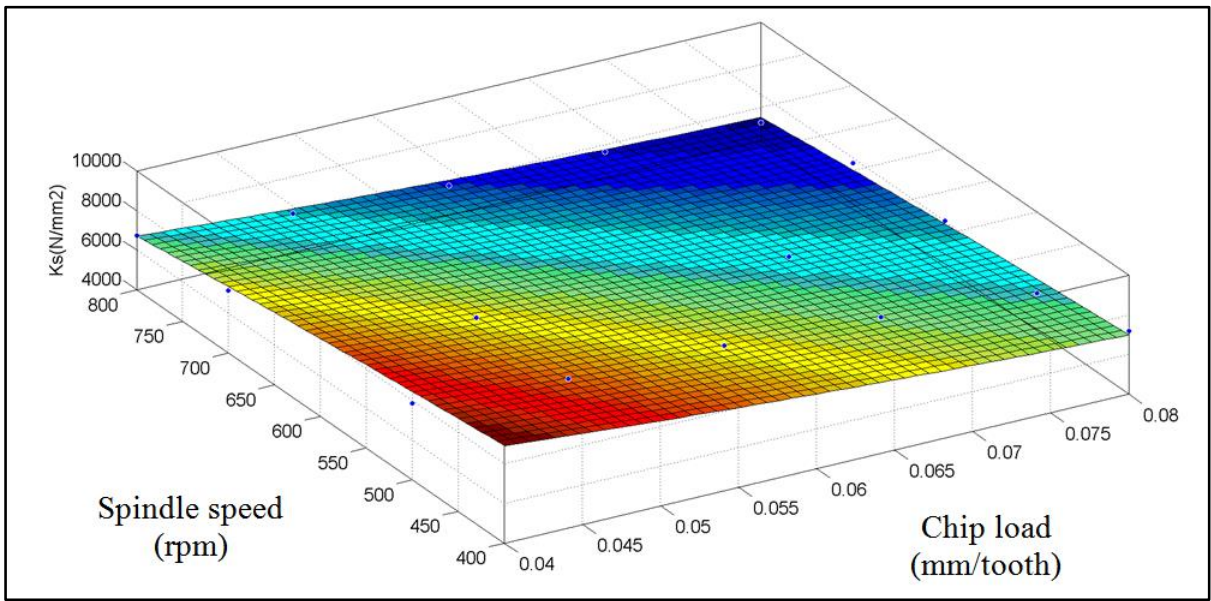

Figure 6. Specific cutting force $k_{s}$ with respect to spindle speed $N$ and feedrate per cutting edge $f_{z}$ based on experimental data by curve fitting.

\section{Conclusions}

Inconel is a commonly employed materail in aerospace and marine industries but difficult to machine. This paper investigated the cutting force for milling process with two-phase experiments. Experiments in phase I are designed based on Taguchi method. Three parameters, the spindle speed, the feedrate per cutting edge and the depth of cut, are used for designing experiments. The results showed that the first two parameters are more important in the cutting force. A phase II exhaust experiments to find a modified cutting force model is designed with spindle speed set from 400 to 800 rpm while the feedrate per cutting edge is set from 0.04 to $0.08 \mathrm{~mm} /$ tooth. The results showed that

(1) There exists a strong size effect in milling Inconel 718. The cutting force changed with the rotating displacement of spindle. Specific cutting force is larger at small thickness of cut and become smaller when the thickness of cut increases. This size effect is critical for machining super alloys similar to Inconel.

(2) A modified cutting force model for milling Inconel 718 is derived as shown in equations 4 and 5 that take spindle speed and feedrate per cutting edge into account. Mean square error of the fitted model is about $4 \%$ and compensates the inaccuracy of conventional cutting force model.

\section{Acknowledgements}

The authors want to express their gratefulness to staffs at the Intelligent Machinery Center of the Industrial Technology Research Institute (ITRI), Taiwan for their assistance on the experimental equipment. Funding for this research has been supported by the Ministry of Science and Technology, Taiwan under contracts MOST104-3011-E-005-002, MOST105-2218-E-194-004 and MOST1062218-E-194-002.

\section{References}

1. M. Rahman, W.K.H.Seah, T.T.Teo, J. of Matrs. Proc. Tech., 63(1-3), 199-204 (1997)

2. I.A. Choudhury, M.A. El-Baradie, Proc. Inst. Mech. Engrs. Part B, 212(3), 195-206 (1998)

3. M.E. Martellotti, Trans. of the ASME, 63, 677-700 (1941)

4. A. Benson, Basic Mechanical Engineering, IV: Machine Tool, http://slideplayer.com/slide/6083347/

5. J. Tlusty, P. MacNeil, Annals of CIRP, 24, 21-25 (1975) 
6. M.C. Shaw, Metal Cutting Principles, $2^{\text {nd }}$ ed., (Oxford Univ. Press, 2004)

7. H.Z. Li, J. of Matrs. Proc. Tech., 180(1-3), 296-304 (2006)

8. M. Nalbant, A. Altin, H.Gökkaya, Materials and Design, 28(5), 1719-1724 (2007)

9. Y.S. Liao, H.M. Lin, J.H. Wang, J. of Matrs. Proc. Tech., 201(1-3), 460-465 (2008)

10. D.G. Thakur, B. Ramamoorthy, L. Vijayaraghavan, Intl. J. Adv. Mfg. Tech., 59(5-8), 483-489 (2012)

11. D.M. D'Addona, S.J. Raykar, M.M. Narke, Procedia CIRP 62, 269-274 (2017)

12. A. Sharman, R.C. Dewes, D.K. Aspinwall, J. of Matrs. Proc. Tech., 118(1), 29-35 (2001)

13. A. Devillez, G.Le Coz, S.Dominiak, D.Dudzinski, J. of Matrs. Proc. Tech., 211(10), 1590-1598 (2011)

14. G. Tauguchi, Taguchi on Robust Technology Development: Bringing Quality Engineering Upstream (ASME Press, 1993) 